\title{
O QUE DIZEM OS PROFESSORES DE ARTE SOBRE AS POLÍTICAS PÚBLICAS INCLUSIVAS ${ }^{1}$
}

\author{
Prof. Dr. ${ }^{a}$ Maria Cristina Da Rosa Fonseca da Silva ${ }^{2}$ \\ Daniela Almeida Moreira ${ }^{3}$ \\ Sabrina Maurília dos Santos ${ }^{4}$
}

\begin{abstract}
Resumo: Esse artigo tem como proposta situar as políticas públicas em âmbito nacional, propulsoras da educação inclusiva e seus desdobramentos com relação ao ensino de arte. No processo de entrevista com os professores de artes identificou-se o discurso dos professores de arte acerca das políticas sobre inclusão. O presente texto faz um recorte deste tema buscando as conexões coma formação de professores de artes Essa reflexão objetiva contribuir com o campo da inclusão e da arte-educação, aproximando as duas temáticas e somando-se as discussões sobre o arte-educação.
\end{abstract}

Palavras Chaves: Educação Inclusiva - Ensino de Artes - Formação de professores

Esse texto resulta da investigação realizada ao longo da pesquisa Construção metodológica do fazer pedagógico de arte: desafios da inclusão, a qual, propôs a análise das concepções de professores de arte sobre a educação inclusiva na rede regular e pública de ensino em Florianópolis e São José. Considerou-se também as metodologias e estratégias de ensino de artes utilizadas pelo professor em sala de aula. A pesquisa reuniu dados através de nove entrevistas com os professores e observação de oito aulas de artes em classes com doze alunos com necessidades educacionais especiais.

Os aspectos aqui apresentados, surgiram a partir de um recorte da análise de dados focados nas falas dos professores entrevistados, em relação as políticas públicas inclusivas. Este recorte foi proposto considerando o entendimento dos professores de arte sobre as iniciativas do poder público em prol da inclusão, caracterizadas como demagógicas, inconsistentes e ineficientes para inserção efetiva do aluno com necessidades especiais na sala regular de ensino. Tendo em vista que a pesquisa concentrou um número de entrevistados com formação em arte durante a década de

\footnotetext{
${ }^{1}$ Projeto de Pesquisa: Construção metodológica do fazer pedagógico de arte: desafios da inclusão ${ }^{2}$ Coordenadora do Projeto de Pesquisa Prof ${ }^{a}$. Dra. Centro de Educação a Distância da UDESC (CEAD) e Professora do Mestrado em Artes Visuais/ CEART/UDESC. Líder do grupo de pesquisa "Educação, Arte e Inclusão". Cnpq.

${ }^{3}$ Bolsista de Iniciação Científica, PIVIC estudante de Artes Visuais do Centro de Artes da UDESC. Membro do grupo de Pesquisa “ Educação, Arte e Inclusão” Cnpq.

${ }^{4}$ Bolsista de Iniciaçao Cientîfica. PIBIC estudante de Artes Visuais do Centro de Artes da UDESC.

Membro do grupo de Pesquisa "Educação, Arte e Inclusão" Cnpq.
} 
1980, observou-se nas falas dos professores de arte, que a formação acadêmica do educador em arte não dispunha de disciplinas, temáticas ou capacitações com abordagens inclusivas, embora na década de 1980, o país teria a atenção voltada para a organização da sociedade civil, a defesa dos direitos humanos, as causas das desigualdades sociais e a inserção do país num cenário globalizado.

Partindo do exposto esse artigo tem como proposta, identificar os elementos propulsores das medidas governamentais em prol da Inclusão Social, situar o contexto nacional da implementação dessas medidas, as implicações dessas medidas, para o ensino de Arte e a para a formação do professor de arte.

\section{Políticas Públicas, o que nos fala a legislação:}

A partir da década de 80, o Brasil segue em processo de redemocratização, depois de duas décadas de regime ditatorial do governo militar, o país adere ao movimento em prol dos Direitos Humanos, mobilizado pelos Tratados Internacionais que preconizavam a erradicação da exclusão social e a promoção da democracia. Essa perspectiva é motivada pela Globalização, a qual, toma o lugar da filosofia taylorista, centrada na individualidade, na maximização da energia humana em prol da produtividade, na fragmentação existente na realidade social. A Globalização torna positiva o cooperativismo, redimensiona a individualidade tendo em vista a diferença, apregoa a comunicação em rede e o avanço das tecnologias a favor da superação das fronteiras entre as sociedades. Na fala de um dos professores: [...É uma pessoa que está comigo... que eи preciso tratar na sua integridade ...] podemos identificar a concepção de sujeito em sua plenitude, a educação incorpora os ditames da ordem.

As formas de governos sensíveis a causa humanitária, serão critério político para admissão em blocos econômicos e estabelecimento de relações sociais com a comunidade internacional. ${ }^{5}$ A Constituição brasileira de 1988, a primeira Constituição Democrática após o governo dos militares, vai assegurar os direitos humanos e o regime democrático. Cabe destacar a fala da professora entrevistada : [... no nosso tempo, não havia mesmo preocupação... os filósofos que passaram a pensar no ser politicamente correto, na multiculturalidade e o respeito a diferença. Eu acho que essa questão da inclusão foi entrando no nosso contexto nos últimos anos, em 1984 não se pensava dessa maneira...], através desse trecho podemos situar o processo de inclusão e seus

${ }^{5}$ BELLISTRIN ([s.a.]) 
desdobramentos relacionados ao sistema de ensino e as tendências pedagógicas em cada época.

Nos anos de 1990, a causa dos direitos humanos tem como marco a $2^{\mathrm{a}}$ Conferência Internacional dos Direitos Humanos em Viena, proposta pela ONU ainda em $1989^{6}$, a Conferência estabeleceu uma relação intrínseca entre democracia, desenvolvimento e direitos humanos, referendando a Declaração Mundial dos Direitos Humanos, elaborada na $1^{\text {a }}$ Conferência em 1948. O Brasil demonstrando atender as recomendações e convenções pressupostas na Conferência de Viena criou o Plano Nacional dos Direitos humanos, documento que sistematiza um programa de ações afirmativas, criação de instrumentos legislativos de promoção de igualdade, mecanismos de inserção e re-inserção social, além de propor um conjunto de ações ao combate da exclusão social contando com a parceria entre a sociedade civil e as três instâncias de governo: federal, estadual e municipal.

Em decorrência das mobilizações dos movimentos sociais e da comunidade educacional organizadas, a educação assume papel importante como instrumento para diminuição das desigualdades sociais e formação do cidadão. ${ }^{7}$ A seguinte fala : [...luta e movimentação, solicitações e pedidos direto a escola para ter um acompanhamento mais próximo, mais próximo de nós, nesse sentido da inclusão...] evidencia a mobilização do educador, tomando parte do movimento que vai culminar na Educação Inclusiva.

A Constituição de 1988, chamada de Constituição Cidadã, ${ }^{8}$ previa a formação desse cidadão, destacando o papel da educação, consagrou conquistas no campo da educação, tais como: gratuidade do ensino público em todos os níveis, percentuais mínimos do orçamento destinados a educação, além de dispor sobre os parâmetro mínimos de competência e de conteúdos a serem garantidos pelo sistema de ensino brasileiro. ${ }^{9}$ A “ universalização do ensino”, tema discutidos internacionalmente, o Brasil vai estabelecer metas e compromissos para a universalização do ensino. ${ }^{10}$

A Conferência Mundial de Educação para Todos, na Tailândia, a qual, resultou na Declaração Mundial sobre Educação para Todos, em defesa do acesso às necessidades básicas de aprendizagem de todos os cidadãos e a promoção de investimento nos

\footnotetext{
${ }^{6}$ ALVES ([s.a.])

${ }^{7}$ SAVIANE (2006)

${ }^{8}$ GIUSEPPE ([s.a.])

${ }^{9}$ FILIPOUSKI e KEHRWALD ([s.a.])

${ }^{10}$ IUMATTI ([s.a.])
} 
sistemas educacionais, além de preconizar o acesso de todos à educação básica, ${ }^{11}$ vai servir de inspiração ao Brasil, participante da Conferência e adepto dos princípios da educação para todos.

Nesse movimento de democratização do ensino visando a educação para todos, o tema Educação Inclusiva ${ }^{12}$ vai ganhar força, reunindo representantes da causa da pessoa com deficiência na Conferência Mundial de Educação Especial, na Espanha, onde é elaborada a Declaração de Salamanca. Este documento estabeleceu diretrizes para a inclusão escolar da criança com necessidades especiais, visando atuar junto aos governantes para garantir os direitos de cidadania para crianças com necessidades especiais. Para o Brasil, a Declaração de Salamanca tornou-se referência na elaboração da Política Nacional para Inclusão das Crianças com Necessidades Especiais” e na instituição de leis referentes a educação especial. ${ }^{13}$

O governo brasileiro em 1996 sanciona a Lei de Diretrizes de Base da Educação Nacional - LDBEN, considerada a Lei maior da Educação Brasileira, denominada Carta Magna da Educação, ${ }^{14}$ vai sintetizar os preceitos das políticas publicas ao longo dos anos 80 e 90, tem como principio: a obrigatoriedade da educação básica, a garantia da gratuidade escolar, a melhoria da qualidade educacional, da formação e capacitação dos docentes, a autonomia universitária, a formação básica do cidadão e a universalização do ensino fundamental. ${ }^{15}$ Além de pressupostos de modernização da gestão da escola, atribuição do professor, do aluno e da família, o papel de agente no processo de ensino aprendizagem, também dispõe sobre o acesso as novas tecnologias e a educação especial como modalidade escolar oferecida pela rede regular de ensino, é a primeira vez que a legislação considera a educação especial em capítulo próprio.

Ainda na década de 1990 estará na pauta do MEC, a elaboração dos Parâmetros Curriculares Nacionais - PCN(s), que tiveram aprovação apenas em 1998. ${ }^{16}$ As reformas ocorridas neste período levaram em conta o Plano decenal de educação formatado no governo de Fernando Henrique Cardoso a partir das definições neoliberais constituídas pelos países ricos para a educação dos países pobres.

Os $\mathrm{PCN}(\mathrm{s})$ terão como orientação a $\mathrm{LDB}$, primando pelo respeito a diversidade, a extensão do acesso à escola, obrigatoriedade da escolarização até o Ensino Médio,

\footnotetext{
${ }^{11}$ Idem apud acima ([s.a.]) IUMATTI

12

${ }^{13}$ IUMATTI ([s.a.])

${ }^{14}$ FAGUNDES ([s.a.])

${ }^{15}$ Idem apud acima ([s.a.]) FAGUNDES

${ }^{16}$ FILIPOUSKI e KEHRWALD ([s.a.])
} 
inclusão de alunos com deficiência na rede regular e articulação das três instâncias de poderes para efetivação das reformas no ensino, ${ }^{17}$ além de servir como referência para práticas educativas e a implementação de um currículo com características básicas.

Até aqui acompanhamos o histórico de ações e proposições do poder público numa perspectiva inclusiva, no entanto, nas falas dos professores de artes entrevistados, aparece como consenso, que tanto o professor, quanto a instituição de ensino, não estão preparados para receber o aluno com necessidades especiais: [... dar respaldo suficiente para essa criança, pra ela não se sentir ainda mais descriminada no processo. Acho que as instituições ainda não estão preparadas para receber essa criança, os professores não estão preparados...]

Pode-se analisar este contexto e identificar alguns aspectos que podem responder a esta problemática, identifica-se a formação inadequada para as políticas de inclusão, dos professores de artes, a falta de estrutura física e pedagógica das escolas e os baixos salários dos profissionais da educação.

\section{A formação inclusiva do professor de Arte:}

No final dos anos de 80 e ao longo da década de 90 os ideais da Globalização, apregoavam uma sociedade solidária, plural, tolerante as diferenças, co-participativa em prol da coletividade. Esse novo modelo de sociedade procurava superar a filosofia taylorista com pressupostos de individualidade, maximização do tempo, do espaço e da energia humana, de fragmentação dos processos e do conhecimento, ambos a serviço da produtividade. ${ }^{18}$

A educação assumiu princípios semelhantes à sistemática do setor produtivo, os estudantes desestimulados a intervenção, a reflexão e a crítica, terão a aprendizagem reduzida a um banco de dados sem significados e a execução de tarefas, quanto ao professor, não compete intervenção, seja na construção de um currículo seja na propostas pedagógicas, sua a atribuição é transmitir o conhecimento, ter como dever, fazer com que aos alunos memorizem os conteúdos, importando os resultados, como se fossem pagamento pelo trabalho empenhado. ${ }^{19}$ Os conteúdos das disciplinas descontextualizados, alheios ao cotidiano do aluno, trabalhados de maneira isolada, sem propiciar a compreensão da realidade e do próprio processo de ensino aprendizagem,

\footnotetext{
${ }^{17}$ FILIPOUSKI e KEHRWALD ([s.a.])

${ }^{18} \operatorname{CASSIA~([s.a.])}$

${ }^{19}$ SANTOMÉ ([s.a.])
} 
previa a necessidade de transformações. A escola reproduzia a mesma sistemática dos processos produtivos, resultando na ineficiência do ensino-aprendizado e responsável pela exclusão social, uma vez que, não proporciona formação ideal para uma inserção igualitária no sistema produtivo. ${ }^{20}$

A LDB reestruturada na década de 90, tinha como objetivo reformulação de todos os níveis de ensino, para atender as transformações vigentes da sociedade naquele momento, vai assegurar obrigatoriedade e gratuidade escolar, a formação e a valorização do profissional da educação, a universalização do ensino fundamental.Vai depositar nos conteúdos do currículo a expectativas de qualificação do ensino nacional, o que vai dar origem aos $\operatorname{PCN}(s)$. No que se refere a educação inclusiva, a educação especial reconhecida como modalidade do ensino, terá como prerrogativas o acesso da criança com necessidades especiais ao ensino regular, portanto o sistema de ensino e o público terão um novo perfil, o que implica estruturação da escola e capacitação do corpo docente para atender as novas expectativas no campo da educação.

Em se tratando do ensino de arte, na reelaboração da LDB, o conteúdo da disciplina de arte será alvo de críticas, vai propor o ensino extracurricular da arte não compreendido pela grade obrigatória, ${ }^{21}$ isso mobilizou profissionais da arte educação, reuniu teóricos em simpósios, seminários, conferência organizados por todo o Brasil, em torno da problemática da qualidade do ensino de arte, o conteúdo da disciplina e o fundamento da arte como campo de conhecimento ressaltando como essencial ao currículo escolar. ${ }^{22} \mathrm{~A}$ articulação dos arte-educadores culminou com a sanção da LDB, a obrigatoriedade da disciplina de Arte até o ensino médio, os $\mathrm{PCN}(\mathrm{s})$ de Arte contemplando as linguagens visuais, da dança, do teatro e da música, além de caracterizar o papel para cada docente e sua respectiva área e linguagem de atuação. No que se refere a capacitação inclusiva, de forma geral, aponta a formação continuada sem indicar capacitação específica ${ }^{23}$.

\section{Políticas públicas e a formação inclusiva do professor de arte no cotidiano da escola regular:}

A pesquisa que teve como espaço de coleta de dados, a sala de aula de arte com alunos com necessidade especiais da rede regular de ensino em Florianópolis e São

\footnotetext{
${ }^{20} \operatorname{CASSIA}([$ s.a. $])$

${ }^{21}$ ROSA (2005)

${ }^{22}$ MENEGHETTI ([s.a.])

${ }^{23}$ FILIPOUSKI e KEHRWALD ([s.a.])
} 
José, em parte, consistia em observações de oito aulas de cada professor e seu respectivo aluno e entrevistas com os professores voluntários participantes da pesquisa. Destacou-se das observações e falas contidas nas entrevistas, aspectos referentes a proposta de Inclusão e o ensino de arte em sala da rede regular, as características da metodologia do professor e o reflexo da pretensa formação inclusiva e as políticas públicas e a inserção do aluno com necessidades especiais na sala regular do ensino.

No acompanhamento das aulas de arte em salas inclusivas, de uma maneira geral, foi possível observar que a dinâmica da aula segue sem qualquer distinção entre os alunos, como pode ser percebido nessa fala: [... parto do princípio que eu tenho 30 alunos iguais com necessidades didático pedagógico distintas...]. O aluno tem seu reconhecimento como sujeito participativo: [...Ele está ali e tem vida produtiva, por isso que é inclusão social ...], embora exista percepções mais focadas nas limitações do que nas possibilidades: [...Em uma conversa prévia com a professora, ela diz que que não sente o interesse de $\mathbf{J}$ junto as suas aulas... as coleguinhas fazem a atividade da $\mathbf{J}$ e quando esta percebe que a amiguinha não está ali e ela mesma tem que fazer o trabalho J fica desestimulada...], bem como entendimentos mais pragmáticos em relação a Inclusão, demonstrado nessa fala: [...alunos com necessidades especiais estarem dentro da escola, é importante conviver com as outras crianças, mas é só isso que tem de importante para ele dentro da escola?...].

É constatação em dados obtidos nas entrevistas e no contexto das aulas de arte observadas, que a proposta inclusiva insere o aluno na sala regular mas, a formação do professor não acompanha o processo de inclusão. As entrevistas, em sua grande maioria, os professores relatam que a formação acadêmica do professor de arte não contemplou a temática Inclusão, afirmam em suas falas: [...O tema das necessidades especiais não estava situado no currículo. Dentro do meu processo tive capacitações após a formatura...], [...o tema inclusão no currículo era inexistente, não me preparei para atuar na prática com esses alunos...].

A experiência e a capacitação do professor de arte, para atender o aluno com necessidades especiais, se dá concomitantemente: [... A gente vai atrás de orientador, atrás de texto. É! Eu tenho que abraçar essa causa....], [... Eu me lembro que eu tive um aluno autista, eu fui para a internet para buscar texto sobre autismo...], [...buscando experiências bem sucedidas, vídeos, buscar contato com pessoas que vivenciaram essas questões, como os próprios pais, conversando para conhecer o histórico dessa criança...]. No que se refere aos dispositivos para capacitação do professor, que entre a 
maioria dos entrevistados, aconteceu durante a atuação, caracteriza-se de forma teórica: [...nós tivemos várias palestras com profissionais mais diversos desde a área médica até a área pedagógica, trabalhando com palestras e oficinas, inclusive o pessoal da educação especial de São José veio pra falar sobre materiais adaptados...], [...a escola ofereceu capacitação através de palestras, em um dado momento do processo de inclusão na escola, mas não deu continuidade, mesmo assim não havia momento entre os professores...] .

A prática pedagógica em arte, nas aulas observadas tem características muito variadas, talvez seja as implicações da capacitação da matriz curricular da licenciatura em arte que não contempla a capacitação inclusiva, ocasionando um preparo inconsistente do arte educador. Desde as práticas mais tradicionais tais como releitura: [...conversam sobre a releitura, a professora dá auxílio na técnica, J não está envolvida com o trabalho...], [...A professora senta-se à mesa de A para ajudá-lo a fazer o cartaz com os recortes de revista...]

Considera-se que as entrevistas que levantam as falas dos professores são de fundamental importância para a formação de professores nas universidades e no ensino de arte de modo geral. Assim, é possível dizer que mesmo sem formação inclusiva o professor de arte mostra que conhece as políticas públicas de inclusão. Percebeu-se que um dos desafios colocados é transformar este pensamento critica acerca da inclusão se transforme em práticas pedagógicas de qualidade. No movimento de inclusão a responsabilidade não é só do professor, o compromisso é coletivo, educacional e social, o professor de arte constrói a sua parte.

\section{Considerações finais:}

No processo de implementação de políticas públicas inclusivas no campo do ensino de arte, considerando o aparato legislador, teve efeito transformadores e inovadores, mas destacou-se no andamento da pesquisa, que os investimento ainda não abrangem a equipe técnica e instalações onde se efetua a proposta de educação inclusiva no ensino de arte.

Tanto a escola quanto o professor de arte foi destacado como não preparados para atender o aluno com necessidades especiais, embora o histórico traçado ao longo desse artigo, tenha apontado uma série de documentos e medidas de cunho normatizador e implementador da proposta inclusiva. Mesmo com este cenário o contexto escolar ainda se apresenta de forma muito insipiente. 
O ensino de arte não pode ser caracterizado como seguidor dos princípios de inclusão, tendo em vista que na maioria das entrevistas os professores não tiveram abordagem da Inclusão na formação. Assim como a formação continuada se dá concomitantemente ao contato com o aluno, colocando o professor numa situação constrangedora e o estudante numa posição de cobaia. No campo da infra-estrutura a escola ainda conta com o improviso, no espaço físico, no material pedagógico, nos mobiliários para atender esse aluno, portanto uma inclusão caracterizada por colocar o aluno na escola regular para aí então programar e estruturar-se para receber o aluno com necessidades especiais.

Conclui-se o presente texto apontando que o universo da pesquisa revelou uma grandeza de dados que podem gerar uma quantia maior de reflexões e análises sobre a problemática de inclusão no ensino de arte. Por outro lado o texto, por sua formatação não comporta a amplitude da investigação que se apresentarão por meio de diversos artigos.

\section{Referencial Bibliográfico:}

ALVES, José Augusto L O Significado Político da Conferência de Viena sobre os direitos humanos .[S.I.:s.a.]. Disponível em: http://www.prac.ufpb.br/. Acesso em 12. junho.2008.

BALlESTRIN, Maria Aragão. Direitos Humanos, Estado e Sociedade Civil no Governo de FHC (1994 2002) .[S.I.:s.a.]. Disponível em: www.senado.gov.br/sf/senado/ilb/pdf . Acesso em 12.junho.2008

CASSIA, Rita Ribeiro Barbosa de. Autonomia da educação na construção da sociedade "inclusiva": A reforma curricular no Brasil.Campinas. [s.a.]. Disponível em: http://ps.unq.edu.ar/resumenes/962.doc

FAGUNDES, Augusta Isabel Junqueira. LDB - Dez anos em ação. .[S.I.:s.a.]. Disponível em: http://www.ipae.com.br/ldb/augustafagundes.doc. Acesso em: 12.junho. 2008

FILIPOUSKI, Ana e KEHRWALD, Isabel. P. Educação brasileira depois dos PCN: visão de futuro. .[S.I.:s.a.]. Disponível em: www.artenaescola.org.br/forum/topico.php. Acesso em 09.junho.2008.

GIUSEPPE, T. A Universidade e a Educação aos Direitos Humanos.[S.I.:s.a.]. Disponível em: http://www.prac.ufpb.br/. Acesso em 12. junho.2008.

IUMATTI, Ana Beatriz Teixeira. A respeito da inclusão escolar no Brasil.[S.I.:s.a.]. Disponível em: http://www.promenino.org.br/TabId/77/Conteudo. Acesso em 09.junho.2008. 
MENEGHETTI, Sylvia Bojunga. Contexto Nacional: As principais mudanças políticas e conceituais na visão dos arte-educadores. .[S.I.s.a.]. Disponível em: www.arteaescola.com.br. Acesso em 08.junho. 2008.

FONSECA da SILVA, Maria Cristina da Rosa. A Formação de professores de arte: diversidade e complexidade pedagógica. Florianópolis: Insular, 2005.

SANTOMÉ, Torre Jurjo. Globalizaçãoe Interdisciplinaridade - o currículo integrado. [S.I.:s.a.]. Disponível em: www.senado.gov.br/sf/senado/ilb/pdf . Acesso em 12.junho.2008

SAVIANE, Dermeval. O legado Educacional do "Longo Século XX" Brasileiro.Campinas,SP:Autores Associados, 2006. 